\title{
lodine status and thyroid function among Spanish schoolchildren aged 6-7 years: the Tirokid study
}

L. Vila ${ }^{1}$, S. Donnay ${ }^{2}$, J. Arena ${ }^{3}$, J. J. Arrizabalaga ${ }^{4}$, J. Pineda $^{5}$, E. Garcia-Fuentes ${ }^{6}$, C. García-Rey ${ }^{7}$, J. L. Marín ${ }^{8}$, M. Serra-Prat ${ }^{9}$, I. Velasco ${ }^{10}$, A. López-Guzmán ${ }^{11}$, L. M. Luengo ${ }^{12}$, A. Villar ${ }^{13}$, Z. Muñoz ${ }^{14}$, O. Bandrés ${ }^{15}$, E. Guerrero ${ }^{16}$, J. A. Muñoz ${ }^{17}$, G. Moll $^{18}$, F. Vich $^{18}$, E. Menéndez ${ }^{19}$, M. Riestra ${ }^{20}$, Y. Torres ${ }^{1}$, P. Beato-Víbora ${ }^{12}$, M. Aguirre ${ }^{21}$, P. Santiago $^{22}$, J. Aranda $^{23}$ and C. Gutiérrez-Repiso ${ }^{24}$

${ }^{1}$ Endocrinology and Nutrition Department, Hospital de Sant Joan Despí Moisès Broggi, Jacint Verdaguer 90, o8970 Sant Joan Despí (Barcelona), Spain

${ }^{2}$ Endocrinology and Nutrition Department, Fundación Hospital Alcorcón, Calle Budapest 1, 28922 Alcorcón, Madrid, Spain ${ }^{3}$ Pediatrics Department, Hospital Universitario Donostia, Doctor Begiristain Kalea, 117, 20080 Donostia, Gipuzkoa, Spain ${ }^{4}$ Endocrinology and Nutrition Department, Hospital Universitario Araba Unibertsitate Ospitalea, Calle Francisco Leandro de Viana 1 Kalea, 01009 Vitoria-Gasteiz, Araba, Spain

${ }^{5}$ Endocrinology and Nutrition Department, Hospital García Orcoyen, C/Santa Soria, 22-31200 Estella, Spain

${ }^{6}$ Digestive Diseases Unit, Hospital Carlos Haya, Avenida Carlos Haya, s/n, 29010 Málaga, Spain

${ }^{7}$ Medical Department, Merck S.L., Calle de María de Molina, 40, 28006 Madrid, Spain

${ }^{8}$ Newborn Screening Laboratory, Biochemical and Molecular Genetics Department, Hospital Clinic, Villarroel, 170,08036 Barcelona, Spain

${ }^{9}$ Research Unit, Hospital de Mataró, Consorci Sanitari del Maresme, Carrer Prolongació Cirera, s/n, 08304 Mataró, Barcelona, Spain

${ }^{10}$ Pediatrics, Obstetrics \& Gynecology Unit, Hospital Riotinto, Avenida Esquila, 5, 21660 Minas de Riotinto, Huelva, Spain

${ }^{11}$ Endocrinology and Nutrition Department, Complejo Asistencial de Avila, Av. Juan Carlos I, s/n, 05071 Avila, Spain

${ }^{12}$ Endocrinology and Nutrition Department, Hospital Universitario Infanta Cristina, Av. Elvas, s/n, 06006 Badajoz, Spain

${ }^{13}$ Endocrinology and Nutrition Department, Hospital Clinico de Valladolid, Calle Ramón y Cajal, s/n, 47005 Valladolid, Spain

${ }^{14}$ Area Básica de Salud (ABS) Ariza, C/De La Paz Ariza, 50220 Zaragoza, Spain

${ }^{15}$ Endocrinology and Nutrition Department, Hospital Royo Villanova, Avda. San Gregorio, s/n, 50015 Zaragoza, Spain

${ }^{16}$ Endocrinology and Nutrition Department, Hospital Rio Carrión, Av. Donantes de Sangre, s/n, 34005 Palencia, Spain

${ }^{17}$ Área Básica de Salud (ABS) de la Seu d'Urgell, Pg. Joan Brudieu, 8, 25700 La Seu d'Urgell, Lleida, Spain

${ }^{18}$ Endocrinology and Nutrition Department, Hospital de Inca, Carretera Vella de Llubi, S/N, O7300 Inca, Islas Baleares, Spain

${ }^{19}$ Endocrinology and Nutrition Department, Hospital Central de Asturias, Avenida de Roma, s/n, 33011 Oviedo, Asturias, Spain

${ }^{20}$ Endocrinology and Nutrition Department, Hospital de Cabueñes, Camino de los Prados 395, 33394 Gijón, Spain

${ }^{21}$ Endocrinology and Nutrition Department, Hospital General de Ciudad Real, Calle del Obispo Rafael Torija, s/n, 13005

Ciudad Real, Spain

${ }^{22}$ Endocrinology and Nutrition Department, Complejo Hospitalario de Jaén, Av. del Ejército Español, 10, 23007 Jaén, Spain

${ }^{23}$ Endocrinology and Nutrition Department, Hospital Virgen de la Luz de Cuenca, Hermandad Donantes de Sangre, s/ $n$,

16002 Cuenca, Spain

${ }^{24}$ Endocrinology and Nutrition Department, Institute of Biomedical Research of Málaga (IBIMA), Hospital Regional

Universitario de Málaga, Plaza del Hospital Civil s/n, 29009 Málaga, Spain

(Submitted 25 October 2015 - Final revision received 22 January 2016 - Accepted 3 February 2016 - First published online 10 March 2016$)$

\section{Abstract}

I deficiency is still a worldwide public health problem, with children being especially vulnerable. No nationwide study had been conducted to assess the I status of Spanish children, and thus an observational, multicentre and cross-sectional study was conducted in Spain to assess the I status and thyroid function in schoolchildren aged 6-7 years. The median urinary I (UI) and thyroid-stimulating hormone (TSH) levels in whole blood were used to assess the I status and thyroid function, respectively. A FFQ was used to determine the consumption of I-rich foods.

Abbreviations: AC, autonomous communities; ID, iodine deficiency; IS, iodised salt; P25 and P75, 25th and 75th percentiles; RV, reference values; TSH, thyroidstimulating hormone; UI, urinary iodine; UIC, urinary iodine concentration.

* Corresponding author: L. Vila, fax +34 9174544 44, email Lluis.Vila@sanitatintegral.org 
A total of 1981 schoolchildren ( $52 \%$ male) were included. The median UI was $173 \mu \mathrm{g} / \mathrm{l}$, and $17 \cdot 9 \%$ of children showed UI $<100 \mu \mathrm{g} / \mathrm{l}$. The median UI was higher in males $(180.8 v .153 .6 \mu \mathrm{g} / \mathrm{l} ; P<0 \cdot 001)$. Iodised salt (IS) intake at home was $69 \cdot 8 \%$. IS consumption and intakes of $\geq 2$ glasses of milk or 1 cup of yogurt/d were associated with significantly higher median UI. Median TSH was $0.90 \mathrm{mU} / \mathrm{l}$ and was higher in females $(0.98 v .0 .83 ; P<0.001)$. In total, $0.5 \%$ of children had known hypothyroidism (derived from the questionnaire) and $7.6 \%$ had TSH levels above reference values. Median TSH was higher in schoolchildren with family history of hypothyroidism. I intake was adequate in Spanish schoolchildren. However, no correlation was found between TSH and median UI in any geographical area. The prevalence of TSH above reference values was high and its association with thyroid autoimmunity should be determined. Further assessment of thyroid autoimmunity in Spanish schoolchildren is desirable.

\section{Key words: Iodine status: Iodine deficiency: Thyroid function: Urinary iodine}

I deficiency (ID) is still a worldwide public health problem ${ }^{(1)}$. A wide variety of disorders results from ID, ranging from goitre and psychomotor development retardation up to cretinism in more severe cases. ID is considered the most common cause of preventable mental impairment worldwide ${ }^{(2)}$. Thyroid hormones produced by the mother have a key role in brain development and maturation of the fetus ${ }^{(3)}$; thus, a low concentration of maternal thyroid hormones negatively impacts the health of the fetus. ID could be involved in this situation, and thus it could be prevented by adequate I intake to meet the increased I needs during pregnancy. It has been reported that mild or moderate ID during pregnancy is associated with low intelligence quotient $(\mathrm{IQ})^{(4)}$. Likewise, higher prevalence of goitre, lower IQ and increased auditory threshold have been detected among children with insufficient I intake ${ }^{(4,5)}$.

Use of iodised salt (IS) is one of the best methods to adequately fulfil I requirements ${ }^{(2)}$, and has been accessible to the Spanish population, with an I content of $60 \mathrm{mg} / \mathrm{kg}$, since 1983. IS consumption has always been voluntary and, except for some regions, no comprehensive public health programme has been implemented to promote $\mathrm{it}^{(6)}$. The WHO considers Spain as a zone with an adequate I intake ${ }^{(7)}$, based on local/regional studies conducted in the late 1990s, early 2000s and later ${ }^{(6,8)}$. However, until now, no national study has been conducted in Spanish schoolchildren. The aforementioned regional studies coincided with a remarkable increase in the consumption of IS and other sources of I, such as dairy products, and described median urinary I (UI) within the World Health Organization ${ }^{(2)}$ range corresponding to an adequate I intake in school-age children $(100-199 \mu \mathrm{g} / \mathrm{l})$. There is no information concerning the I content in food products, with the exception of milk $^{(9)}$ despite the use of flour supplemented with IS by some bakeries.

The assessment of ID disorders is the first step towards achieving the goal of their sustainable elimination. Children are a sensitive population to ID; in fact, data from two independent surveys of micronutrient consumption among European children have shown that maximum and minimum average I intakes were below the reference standard for both sexes in the east and west ${ }^{(10)}$. It was necessary to assess the current I status of the Spanish children population, along with its geographical distribution. This would in turn facilitate the implementation of targeted public health campaigns.

Thyroid hormones are involved in somatic growth, neurodevelopment and metabolic pathways, which are essential during childhood ${ }^{(11)}$. In the last few years, thyroid function has been studied in paediatric groups for its relationship with obesity $^{(12)}$ or diabetes type $1^{(13)}$, but nationwide studies in paediatric populations are not common ${ }^{(14)}$. In spite of the fact that neonatal hypothyroidism screening is universal in Spain, little information is available on the prevalence of thyroid dysfunction among healthy Spanish schoolchildren. The present study also aimed to generate normative data for thyroid function in school-age children in our country.

\section{Methods}

\section{Participants and study design}

An observational, multicentre and cross-sectional study was conducted in the seventeen regions, autonomous communities (AC), compiling Spain, to assess the I status of children (primary objective), prevalence of $\mathrm{UI}<100 \mu \mathrm{g} / \mathrm{l}$ and thyroid disorders in schoolchildren aged 6-7 years. Each Spanish AC is divided into one or more provinces. In $\mathrm{AC}$ with one single province, the one was selected for the study. In AC with two to four provinces, two provinces were randomly selected, and in AC with more than four provinces three were randomly selected for the study. The capital of each province was selected by default for sampling. In addition, one of the province towns having 2000-20000 inhabitants was randomly selected. One school in the capital and one in the chosen town were randomly selected, and all schoolchildren of the first grade of primary school, which corresponds to 6-7-yearold children, were recruited (each school had one or two firstgrade classes with twenty-five students each). Children from the capital represented the urban population, whereas those from the smaller town represented the rural population. The recruitment was conducted over 2 years (2010 and 2011) during the school year period (October to December and January to June).

\section{Variables assessed}

The main objective of the present study was to establish the I status of children by assessing the median UI concentration (UIC) of the population. In addition, parents or legal guardians answered a questionnaire, and blood thyroid-stimulating hormone (TSH) levels of the children were also measured. The parents filled in a questionnaire, which included questions about parents' birthplace and education, family or child history of goitre or thyroid dysfunction, medical treatments used, I use for wound disinfection in the last month, surgery in the last 6 months and consumption of IS and other I-rich foods. Foods with known high I content were chosen, especially dairy products ${ }^{(9)}$ and sea fish. Some studies have shown that I supplements for egg-laying chickens increase the I content in eggs, which might contribute to increased I intake in the population ${ }^{(15)}$. The FFQ was designed to assess the 
frequency of consumption and portion size of I-rich foods: milk (number of glasses per $\mathrm{d}$ ) and yogurt (number of cups of yogurt per d); eggs (number per week); fish and cheese (times per week of consumption); and IS (used for cooking: yes/no). Parents were requested in the questionnaire to look at the salt package label to check whether it was iodised or not. The consistency of responses over time, of the six questions of our simplified FFQ, was analysed by a test-re-test, which was conducted in forty-one parents of children aged 6-7 years. Concordance rates varied between $0 \cdot 71$ and 0.95 . The results were also expressed in 'dairy servings'. A single serving was considered as one glass of milk (200-250 ml) or two yogurt cups ( $250 \mathrm{ml}$ total). In Spain, the yogurt cups consumed by children have a volume of $125 \mathrm{ml}$ each. In the 'Results' section, the frequency of consumption of foods has been categorised according to the recommendations of the Spanish Society of Community Nutrition $^{(1)}$ : fish consumption, $\geq 3$ times/week; egg consumption, 3 units/week; and dairy consumption, $\geq 2$ servings/d.

The primary variable was the median UI of the population. The World Health Organization ${ }^{(2)}$ considers a median value of UI between 100 and $199 \mu \mathrm{g} / \mathrm{l}$ as an adequate I status in schoolchildren, a value $<100 \mu \mathrm{g} / \mathrm{l}$ as insufficient (50-99 $\mu \mathrm{g} / \mathrm{l}$, mild ID; 20-49 $\mu \mathrm{g} / \mathrm{l}$, moderate ID; $<20 \mu \mathrm{g} / 1$, severe ID) and values $\geq 200 \mu \mathrm{g} / 1$ as above requirements ( $\geq 300 \mu \mathrm{g} / \mathrm{l}$, excessive). A $20-\mathrm{ml}$ non-fasting sample of urine was obtained from each participant for UI assessment. Each sample was stored in a portable refrigerator and was subsequently frozen at $-20^{\circ} \mathrm{C}$. Samples were transported to the Malaga Biomedical Research Institute (Hospital Regional Universitario Carlos Haya, Malaga, Spain) for analysis in a container with dry ice to ensure that they stayed frozen and were stored again at $-20^{\circ} \mathrm{C}$ until processing. The laboratory used the modified Benotti and Benotti method for UI determination. A previous digestion of the urine sample was made with chloric acid, followed by the Sandell-Kolthoff reaction, in which I acts as a catalyst for the reduction of Ce (IV) to Ce (III) by As (III). The intra- and inter-assay CV were 2.01 and $4.53 \%$, respectively. The UI assay is subjected, three times a year, to a programme of external quality assessment for the determination of I in urine by the Spanish Association of Neonatal Screening. We performed the quality control in triplicate and the reference material was Seronorm ${ }^{\mathrm{TM}}$ Trace Elements Urine (SERO AS), with a mean $z$ score of $0 \cdot 3$.

TSH was assessed in whole blood dried on Whatman 903 filter paper (Whatman Neonatal Screening cards are manufactured and quality released in compliance with the FDA Quality System Regulation) and submitted to a fluoroimmunometric assay (AutoDELFIA $^{\mathrm{TM}}$ Neonatal hTSH test kit; PerkinElmer Inc.) at the Newborn Screening Laboratory, Hospital Clínic. The normal range for TSH was $0 \cdot 07-1.82 \mathrm{mU} / \mathrm{l}$, with intra- and inter-assay CV of 1.82 and $3.67 \%$, respectively. A drop of blood was collected from the child, with consent from the child and his or her parents, by a finger stick applied directly onto the filter paper. The drop was allowed to dry at room temperature and the filter paper was stored in an envelope at $4^{\circ} \mathrm{C}$ until it was processed in the laboratory. This sample was obtained at the same time as the urine sample.

\section{Statistical analyses}

According to previous studies conducted in local areas of Spain, the prevalence of ID (UI $<100 \mu \mathrm{g} / \mathrm{l})$ was estimated as $20 \%$.
The sample size needed, assuming an ID prevalence of $20 \%$ and an accuracy of $\pm 1.5 \%$, was 2370 individuals. As it was estimated that $10 \%$ of values would be lost for analysis, the sample size required was 3100 individuals.

Categorical variables were described by absolute and relative frequencies, whereas quantitative variables were described by mean values, medians, standard deviations, percentiles 25 (P25) and 75 (P75) and number of valid cases. The KolmogorovSmirnov test was used to assess whether the variables followed a normal distribution. Missing data were not included in the analyses and were considered as lost.

The UIC was assessed as a continuous variable in the overall population as well as when assessed as a function of another variable (sex, consumption of I-rich foods, geographical area or parents' educational level). The comparison of UI among the groups was performed by the median test. All results obtained by the median test were confirmed by Mann-Whitney or Kruskal-Wallis tests, according to the number of groups (two or more). The association between UI, TSH and consumption of I-rich food units was assessed by Spearman's correlation coefficient.

A binary logistic regression analysis was performed to assess the possible effect of the demographic characteristics and consumption of I-rich foods on UI $\geq 100 \mu \mathrm{g} / \mathrm{l}$. The $\chi^{2}$ test (or exact Fisher's test, when necessary) was used for the exploratory analysis of the possible risk factors in the case of categorical variables, and the median test was used in the case of quantitative variables. Those variables with a $P$ value above 0.20 in the corresponding bivariate analyses were pre-selected. In order to select the definitive model, different methods of variable selection, automatic as well as manual, were tried.

In order to calculate the TSH reference values (RV) of our population, only children without known thyroid disease and a UI between 100 and $200 \mu \mathrm{g} / \mathrm{l}$ were considered. Extreme cases and outliers were excluded following the method of Tukey. The remaining sample showed normal distribution of TSH for the calculation of RV. Thus, the RV were obtained according to the recommendations of the International Federation of Clinical Chemistry $^{(17)}$, by calculating the $95 \%$ CI for the mean of TSH and standard deviations. The prevalence of thyroid dysfunction was operationally defined as the percentages with $95 \%$ CI of children with TSH values above (defined as hypothyroidism) or below (defined as hyperthyroidism) RV. Median TSH has been used for descriptions and comparisons among groups.

The software SPSS version 17 was used for data analyses. The statistical significance level was set at 5\%.

\section{Ethical statement}

The present study was approved by the Ethics Research Committee of Hospital de Mataró (Barcelona, Spain) functioning according to the 3rd edition of the Guidelines on the Practice of Ethical Committees in Medical Research issued by the Royal College of Physicians of London. The parents or legal guardians of the children signed an informed consent after full explanation of the purpose and nature of all procedures and before enrolling the child for the study. The procedures followed were in accordance with the Helsinki Declaration of 1975, as revised in 2008. 


\section{Results}

\section{Description of the population}

A total of 1981 schoolchildren were assessed in eleven AC (Table 1; Fig. 1), covering $74.7 \%$ of the entire Spanish population. The study could not be conducted in the other six AC (Canary Islands, Cantabria, Galicia, La Rioja, Murcia and Valencia) because of administrative constraints.

Table 1 shows the socio-demographic characteristics of the children, along with their geographical distribution. In all, $52 \%$ were male and over half lived in rural areas. In total, $85 \%$ or more of both parents were from Spain and $2 \%$ were uneducated.

Urine and whole blood samples were obtained from 1750 and 1729 children, respectively.

\section{lodine status}

The median UI was 173 (P25-P75 117.5-237.2) $\mu \mathrm{g} / \mathrm{l}$. The percentage of children with UIC within the adequate range (100-199 $\mu \mathrm{g} / \mathrm{l})$ was $44 \cdot 1 \%$ (95\% CI 41.7, 46.4); UI below $100 \mu \mathrm{g} / \mathrm{l}$

Table 1. Socio-demographic characteristics of the population ( $n 1981$ children)

(Numbers and percentages)

\begin{tabular}{|c|c|c|}
\hline & $n$ & $\%$ \\
\hline \multicolumn{3}{|l|}{ Sex } \\
\hline Male & 816 & $52 \cdot 4$ \\
\hline Female & 741 & $47 \cdot 6$ \\
\hline \multicolumn{3}{|l|}{ Area type } \\
\hline Rural & 1046 & $52 \cdot 8$ \\
\hline Urban & 935 & $47 \cdot 2$ \\
\hline \multicolumn{3}{|l|}{ Regions } \\
\hline Andalusia & 48 & 2.4 \\
\hline Aragon & 193 & $9 \cdot 7$ \\
\hline Asturias & 89 & 4.5 \\
\hline Balearic Islands & 93 & 4.7 \\
\hline Castile-La Mancha & 212 & $10 \cdot 7$ \\
\hline Castile-Leon & 328 & $16 \cdot 6$ \\
\hline Catalonia & 177 & 8.9 \\
\hline Madrid & 119 & 6 \\
\hline Navarra & 159 & $8 \cdot 0$ \\
\hline Basque Country & 363 & $18 \cdot 3$ \\
\hline Extremadura & 200 & $10 \cdot 1$ \\
\hline \multicolumn{3}{|l|}{ Father's ethnicity } \\
\hline Native & 1689 & $86 \cdot 8$ \\
\hline Immigrant & 257 & $13 \cdot 2$ \\
\hline \multicolumn{3}{|l|}{ Father's education } \\
\hline Uneducated & 43 & $2 \cdot 2$ \\
\hline Primary education & 607 & $31 \cdot 3$ \\
\hline Secondary education & 770 & 39.7 \\
\hline Higher education & 521 & $26 \cdot 8$ \\
\hline \multicolumn{3}{|l|}{ Mother's ethnicity } \\
\hline Native & 1684 & $85 \cdot 5$ \\
\hline Immigrant & 286 & 14.5 \\
\hline \multicolumn{3}{|l|}{ Mother's education } \\
\hline Uneducated & 33 & 1.7 \\
\hline Primary education & 462 & 23.5 \\
\hline Secondary education & 755 & 38.4 \\
\hline Higher education & 715 & $36 \cdot 4$ \\
\hline \multicolumn{3}{|l|}{ Thyroid disorder } \\
\hline In the child & 15 & 0.8 \\
\hline Familial & 652 & 33.5 \\
\hline I disinfection (last month) & 289 & $14 \cdot 7$ \\
\hline Surgery in the last 6 months & 36 & $1 \cdot 8$ \\
\hline
\end{tabular}

* The sex was not specified in 424 (21.4\%) patients. was detected in $17.9 \%$ (95\% CI 16.1, 19.7) (Fig. 2). UI below $100 \mu \mathrm{g} / \mathrm{l}$ and below $50 \mu \mathrm{g} / \mathrm{l}$ were more frequently observed in girls (61.1 and $57.5 \%$, respectively), in children whose parents had less than high school-level education (21.6 and $30.6 \%$, respectively) and in those children who did not consume IS (37 and $45.7 \%$, respectively). Median UI was significantly higher in males than in females $(181 v .154 \mu \mathrm{g} / 1 ; P<0.001)$ and differed significantly between regions, although none showed median values lower than $100 \mu \mathrm{g} / \mathrm{l}$ (Table 2). UI was not influenced by living area (rural or urban), by parents' birthplace, I use for wound disinfection in the last month or surgery in the last 6 months (data not shown). Nevertheless, median UI from samples collected in spring (178 (interquartile range (IQR) 134-240) $\mu \mathrm{g} / \mathrm{l})$ was significantly higher $(P<0 \cdot 001)$ than UI from samples collected in winter and autumn (150 (IQR 99-226) $\mu \mathrm{g} / \mathrm{l}$ and 153 (IQR 105-219) $\mu \mathrm{g} / \mathrm{l}$, respectively). No samples were collected in summer.

\section{Urinary iodine concentration according to dietary habits}

The prevalence of IS consumption was 69.8\% (95\% CI 68, 72) (Table 2). IS consumption only refers to IS intake at home and not IS that is consumed through processed foods. The median consumption of glasses of milk and yogurt cups per $\mathrm{d}$ was 2 (P25-P75 1-2) for each of the two food products. The median consumption of dairy servings was 2.5 (P25-P75 2-3). In all, $64.8 \%$ of children consumed $\geq 2$ glasses of milk/d. In total, $81 \%$ of children consumed $\geq 2$ dairy servings/d. The median consumption of cheese and saltwater fish was 2 (P25-P75 2-4) and 2 (P25-P75 2-3) times/week, respectively. The median of consumption of egg units per week was 2 (P25-P75 2-3). In all, $41 \%$ of children consumed saltwater fish $\geq 3$ times/week, $45 \cdot 5 \%$ consumed $\geq 3$ eggs/week, and $80 \%$ consumed cheese at least once a week.

Consumption of I-rich foods differed neither between sexes nor between the 231 children who did not provide a urine sample and those who did. There was no association between consumption of saltwater fish, eggs or cheese and higher UI (Table 3).

The group of children who consumed IS showed a significantly higher median UI $(P<0 \cdot 001)$ and a lower percentage of children with $\mathrm{UI}<100 \mu \mathrm{g} / \mathrm{l}(P=0.003)$ compared with the group that did not consume IS (Table 3 ). Intakes of 1 yogurt cup or $\geq 2$ glasses of milk/d were also associated with statistically significant higher median UI and lower prevalence of children with UI $<100 \mu \mathrm{g} / \mathrm{l}$, as compared with no yogurt intake or $<2$ glasses of milk/d (Table 3). Among children who did not consume IS, a significant but weak correlation between the number of glasses of milk and UI was observed $\left(r_{S}=0 \cdot 122 ; P=0.005\right)$ (Fig. 3).

A logistic regression to assess the effect of independent variables on achieving UI $>100 \mu \mathrm{g} / \mathrm{l}$ was performed: consumption of $\geq 2$ dairy servings/d (OR 1.8; 95\% CI 1.02, 3.34; $P=0.043$ ), IS consumption (OR $1.4 ; 95 \%$ CI $1.11,1.90$; $P=0.007$ ) and male sex (OR 1.9; $95 \%$ CI 1.46, 2.47; $P<0.001$ ) showed a significant independent effect.

The combined effect of IS and high milk consumption $(\geq 2$ glasses/d) resulted in a significantly $(P<0 \cdot 001)$ higher 

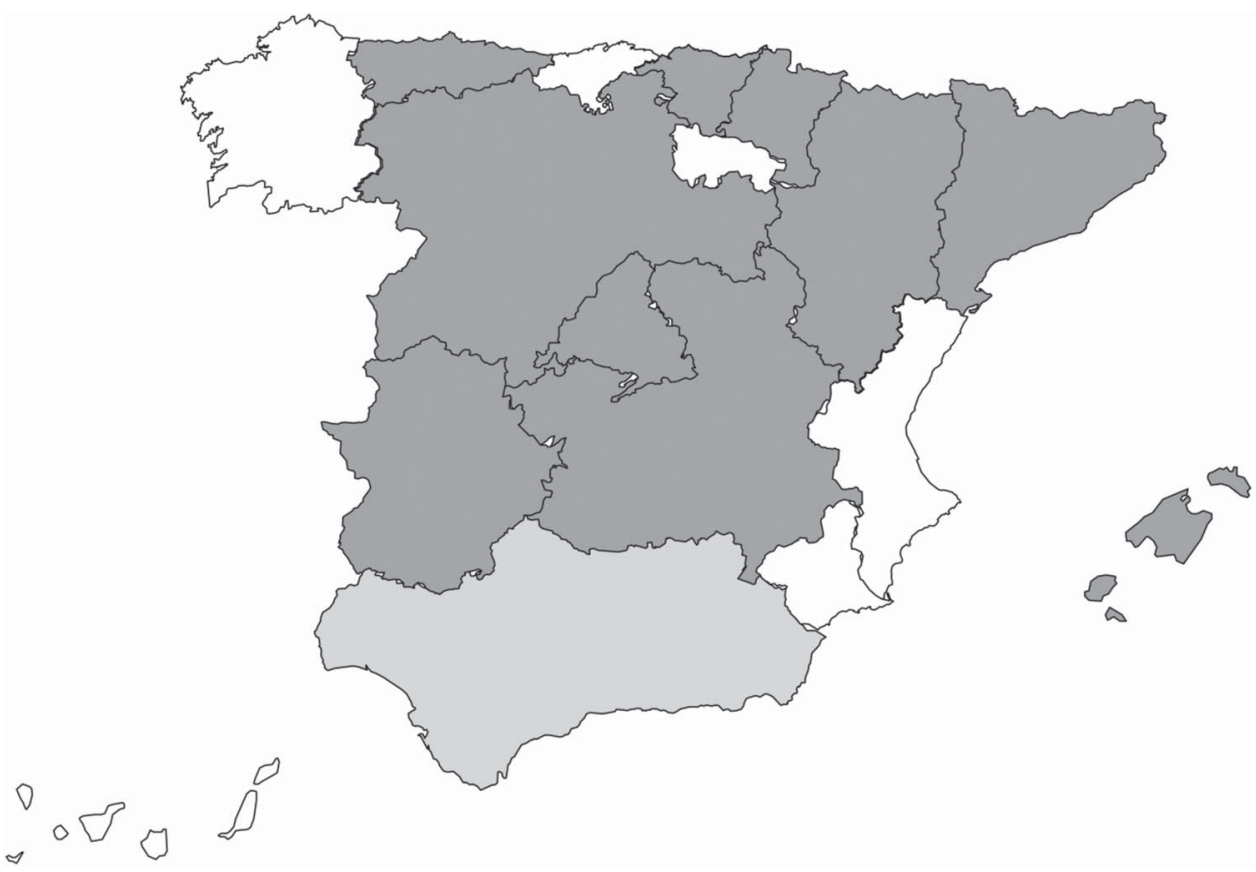

Fig. 1. Map of Spain with regions of study. $\square$, Study completed; $\square$, partial study; $\square$, region not studied.

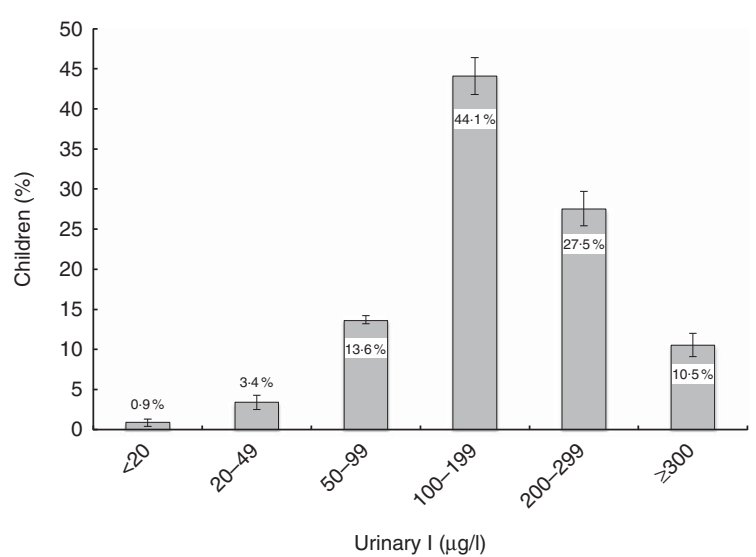

Fig. 2. Urinary iodine $(\mu \mathrm{g} / \mathrm{l})$ distribution among Spanish schoolchildren. Values are percentages, with $95 \% \mathrm{Cl}$ represented by vertical bars.

median UI (189 (P25-P75 128-254) $\mu \mathrm{g} / \mathrm{l})$ than IS or milk consumption alone (165 (P25-P75 116-227) and 167 (P25-P75 113-225) $\mu \mathrm{g} / \mathrm{l}$, respectively). In cases with no IS consumption and low milk consumption ( $<2$ glasses/d), the median UI was significantly lower than in cases with IS consumption alone (146 (P25-P75 97-204) v. 165 (P25-P75 116-227) $\mu \mathrm{g} / \mathrm{l} ; P=0.046)$. Higher parental education was associated with higher median UI $(P<0.001)$ and implicated higher intakes of IS and milk ( $P \leq 0 \cdot 0001$ and $P=0 \cdot 001$, respectively) (data not shown).

\section{Thyroid function}

Only fourteen children presented with or had a history of thyroid disorder: ten had known hypothyroidism (0.5\%; $95 \% \mathrm{CI}$ $0 \cdot 23,0.92$ ) (three were treated with levothyroxine and the other seven showed slightly elevated TSH concentrations), one hyperthyroidism, one known increase in antithyroglobulin antibodies, one non-specified thyroid gland disorder and one surgery for thyroglossal duct cyst.

The TSH RV in whole blood were $0.07-1.75 \mathrm{mU} / 1$ for males, $0 \cdot 14-1.82 \mathrm{mU} / 1$ for females and $0 \cdot 10-1.78 \mathrm{mU} / 1$ for the overall population. Median TSH was 0.90 (P25-P75 0.62-1.28) mU/1 and was higher in females than in males $(0.98 v .0 .83 \mathrm{mU} / \mathrm{l}$; $P<0.001$ ) (data not shown). No correlation was observed between UI and TSH concentrations. The prevalence of thyroid dysfunction is shown in Table 4.

Family history of hypothyroidism (first-, second- or thirddegree relatives) was present in $9.3 \%$ of children (161/1729). In these cases, the median TSH $(0.99 v .0 .89 \mathrm{mU} / 1 ; P=0.036)$ and the prevalence of hypothyroidism (14.9 v. 6.8\%; $P=0.001)$ were significantly higher than in those children with no family history. No correlation was found between prevalence of elevated TSH and median UI in any geographical area. TSH > $3.56 \mathrm{mU} / \mathrm{l}$, twice the upper limit of the reference value (ULRV), was detected in nine cases $(0.52 \% ; 95 \%$ CI $0 \cdot 23,0 \cdot 98)$.

\section{Discussion}

This is the first population-based study conducted to assess the UI in schoolchildren of Spain as a whole. The median UI observed $(173 \mu \mathrm{g} / \mathrm{l})$ indicates an adequate I-related nutrition in schoolchildren, according to World Health Organization ${ }^{(2)}$ criteria. This fact reflects the substantial change in I intake experienced by the Spanish population since the introduction of IS in 1983, evolving from being an ID endemic region ${ }^{(18)}$ to a population with adequate median UI in the late $1990 \mathrm{~s}^{(6)}$.

This median UI is higher than that of the Spanish adult population $(117 \cdot 2 \mu \mathrm{g} / \mathrm{l})^{(19)}$, as it has been described in other 
Table 2. Regional distribution of median urinary I (UI) levels, proportion of children with $\mathrm{UI}<100 \mu \mathrm{g} / \mathrm{l}$ and proportion of children consuming iodised salt ${ }^{\star}$ (Medians and 25th-75th percentiles (P25-P75))

\begin{tabular}{|c|c|c|c|c|c|c|c|}
\hline \multirow[b]{2}{*}{ Autonomous communities } & \multirow[b]{2}{*}{$\mathrm{nmd}$} & \multirow[b]{2}{*}{$n$} & \multicolumn{2}{|c|}{ UI $(\mu \mathrm{g} / \mathrm{l})$} & \multirow[b]{2}{*}{$\mathrm{UI}<100 \mu \mathrm{g} / \mathrm{l}(\%)$} & \multirow[b]{2}{*}{$\mathrm{UI}<50 \mu \mathrm{g} / \mathrm{l}(\%)$} & \multirow[b]{2}{*}{ lodised salt consumption (\%) } \\
\hline & & & Median & P25-P75 & & & \\
\hline Asturias & 6 & 83 & 205 & $146-284$ & $12 \cdot 0$ & 0.0 & $77 \cdot 3$ \\
\hline Basque Country & 67 & 296 & 187 & $127 \cdot 4-251$ & $15 \cdot 9$ & $4 \cdot 1$ & 71.4 \\
\hline Navarra & 16 & 143 & 184 & $135-232$ & 11.9 & $2 \cdot 1$ & $60 \cdot 8$ \\
\hline Castile-La Mancha & 13 & 199 & 175 & $118-241$ & $17 \cdot 6$ & 4.5 & 77.8 \\
\hline Extremadura & 21 & 179 & 172 & $122-249$ & 13.4 & 3.4 & $67 \cdot 7$ \\
\hline Aragon & 14 & 179 & 168 & $112-223$ & $20 \cdot 7$ & 3.4 & $80 \cdot 4$ \\
\hline Andalusia & 11 & 37 & 165 & $103-241$ & 21.6 & 13.5 & $75 \cdot 0$ \\
\hline Madrid & 14 & 105 & 165 & $105-235$ & $21 \cdot 0$ & $5 \cdot 7$ & $59 \cdot 6$ \\
\hline Catalonia & 21 & 156 & 163 & $118-218$ & 13.5 & 1.9 & $76 \cdot 0$ \\
\hline Castile-Leon & 43 & 285 & 156 & $96-221$ & $26 \cdot 0$ & $6 \cdot 7$ & 61.1 \\
\hline Balearic Islands & 5 & 88 & 149 & $106-232$ & 20.5 & $6 \cdot 8$ & 65.5 \\
\hline Total & 231 & 1750 & 173 & $118-237$ & 17.9 & 4.3 & $69 \cdot 8$ \\
\hline
\end{tabular}

nmd, Number of subjects with missing data.

* The $P$ values for the differences among regions in median $\mathrm{UI}$, population percentage with $\mathrm{UI}<100$ and $50 \mu \mathrm{g} / \mathrm{l}$ and iodised salt consumption were $P=0.011$ (median test), $P=0.004$ ( $x^{2}$ test), $P=0.016\left(x^{2}\right.$ test) and $P<0.001\left(x^{2}\right.$ test), respectively. The difference is not significant if Andalusia is excluded in case of $\mathrm{UI}<50 \mu \mathrm{g} / \mathrm{l}$.

studies $^{(20)}$, which might be explained by a higher consumption of milk and dairy products among children as compared with adults, as it was observed in the Spanish enKid study $(>500 \mathrm{~g} / \mathrm{d}$ in the 2-5-year-old group $v .350 \mathrm{~g} / \mathrm{d}$ in the $18-24$-year-old group) ${ }^{(21)}$.

The current adequate concentration of UI in Spanish schoolchildren has been achieved by the consumption of IS and also of milk and dairy products, which are known to be important factors influencing UI levels in Spanish children ${ }^{(15,22)}$. Likewise, in a study conducted in Northeast Italy, an adequate I status was achieved only when IS was combined with daily milk intake ${ }^{(23)}$, in agreement with our data showing the higher impact of the combination of daily milk and IS intake on UI than either one alone. Recently, low milk intake has been associated with ID in UK adolescents ${ }^{(24)}$. Although some studies have also shown an influence of fish or egg intakes on $\mathrm{UI}^{(22)}$, their impact in our study was null.

To guarantee an adequate I concentration, the World Health Organization $^{(2)}$ aimed for $>90 \%$ of families to consume IS. A preliminary study ${ }^{(25)}$ has analysed the I content of different IS brands available in the Spanish food market. The mean and median I contents of IS samples were 63.5 (SD 23.0) and 60 (P25-P75 51-70) $\mu \mathrm{g}$ of $\mathrm{I} / \mathrm{g}$ of salt, respectively. The study showed a wide range of variation in I concentrations among different IS brands but did not find significant differences among regions. In Spain, only $70 \%$ of families consume IS and yet the I concentration was adequate; thus, milk, which in Spain has an average I concentration of $259(\mathrm{SD} 58) \mu \mathrm{g} / \mathrm{l}^{(9)}$, and dairy products seem to have supplied the rest of I. Children with IS consumption and intake $<2$ glasses of milk/d showed similar median UI compared with those who consumed $\geq 2$ glasses of milk/d but did not consume IS. Furthermore, children with low milk ( $<2$ glasses) and no IS consumption also showed an adequate median UI, which probably indicates the existence of other I sources. Excessive I concentrations have been associated with increased thyroid volume in response to thyroid dysfunction $^{(26)}$. Our results showed that $10 \%$ of children had UI $>300 \mu \mathrm{g} / \mathrm{l}$ (Fig. 2). Although these data do not necessarily identify a population with I excess, they prompt for close monitoring of the iodisation of salt and of other putative food products. UI also showed seasonal variations from spring (higher UIC) to winter (lower UIC), as previously observed in other studies $^{(27)}$, which might be explained by the variability of I content in milk throughout the year ${ }^{(9)}$.

Boys showed significantly higher median UI than girls, which could be justified by the higher energy and I intake in boys ${ }^{(21)}$; however, the results from the FFQ of boys and girls did not differ significantly.

Nevertheless, a very recent study ${ }^{(28)}$ has warned about how hydration status can interfere with UIC values even in large surveys. This factor must be considered as well as urine volume or body surface area when we consider differences between children and adults, boys and girls or seasonal variations.

This is the first time that TSH RV were assessed in Spanish schoolchildren. Our survey detected high prevalence of elevated TSH (7.6\% overall). Previous studies conducted in two Spanish provinces showed similar data ${ }^{(29,30)}$, which could be explained by the use of adult TSH RV, with a lower upper limit than those of the children ${ }^{(31)}$. However, in our study, we used RV calculated in the study's population itself. The study by Lazar et al. ${ }^{(32)}$, conducted in 121000 children aged 6 months to 16 years, showed lower prevalence of elevated TSH $(3.3 \%)$ than our study, although similar prevalence of cases with TSH concentrations compatible with clinical hypothyroidism. The recent study by Johner et $a l^{(33)}$ has shown an association between higher I intakes and a shift in TSH towards higher levels in children. According to those authors, the high prevalence of elevated TSH observed in our population should not be considered as a higher risk for (subclinical) hypothyroidism. Furthermore, the improved I status in children can be a plausible explanation for a physiological variant, corresponding to an euthyroid situation, with slightly elevated $\mathrm{TSH}^{(33)}$. Only cases with initial highly elevated TSH levels show greater risk of evolving to clinical hypothyroidism ${ }^{(32)}$. In our population, $0.52 \%$ of the children had TSH levels twice the ULRV, and thus were at risk for developing clinical hypothyroidism. Our study 
Table 3. Effects of different variables on ioduria (Numbers and percentages)

\begin{tabular}{|c|c|c|c|c|c|c|c|c|c|}
\hline \multirow[b]{2}{*}{ Variables } & \multicolumn{2}{|c|}{ Children } & \multirow[b]{2}{*}{ Median UI $(\mu \mathrm{g} / \mathrm{l})$} & \multirow[b]{2}{*}{$P \dagger$} & \multicolumn{2}{|c|}{$\mathrm{UI}<100 \mu \mathrm{g} / \mathrm{l}$} & \multirow[b]{2}{*}{$P \ddagger$} & \multicolumn{2}{|c|}{ Correlation: food consumption/UI } \\
\hline & $n$ & $\%$ & & & $n$ & $\%$ & & $r$ & $P$ \\
\hline \multicolumn{10}{|l|}{ Sex } \\
\hline Male & \multirow{2}{*}{\multicolumn{2}{|c|}{$\begin{array}{l}816 \\
741\end{array}$}} & 181 & \multirow[t]{2}{*}{$<0.001^{\star}$} & 119 & $14 \cdot 6$ & \multirow[t]{2}{*}{$<0.001^{\star}$} & \multirow{2}{*}{\multicolumn{2}{|c|}{-}} \\
\hline Female & & & 154 & & 181 & 24.4 & & & \\
\hline \multicolumn{10}{|l|}{ I disinfection } \\
\hline None & 1477 & $85 \cdot 2$ & 174 & \multirow[t]{2}{*}{0.743} & 270 & $18 \cdot 3$ & \multirow[t]{2}{*}{0.240} & \multicolumn{2}{|c|}{-} \\
\hline Yes & 256 & $14 \cdot 8$ & 172 & & 39 & $15 \cdot 2$ & & & \\
\hline \multicolumn{10}{|l|}{ lodised salt } \\
\hline None & 521 & $30 \cdot 2$ & 158 & \multirow[t]{2}{*}{$<0.001^{*}$} & 114 & 21.9 & \multirow[t]{2}{*}{$0.003^{*}$} & \multirow{2}{*}{\multicolumn{2}{|c|}{-}} \\
\hline Yes & 1197 & $69 \cdot 8$ & 180 & & 191 & 16 & & & \\
\hline \multicolumn{8}{|l|}{ Fish consumption } & \multirow[t]{3}{*}{-0.016} & \multirow[t]{3}{*}{0.498} \\
\hline$<3$ times /week & 1018 & 59 & 174 & \multirow[t]{2}{*}{0.405} & 173 & 17 & \multirow[t]{2}{*}{0.257} & & \\
\hline$\geq 3$ times/week & 706 & 41 & 171 & & 135 & $19 \cdot 1$ & & & \\
\hline \multicolumn{8}{|l|}{ Glasses of milk } & 0.117 & $<0.0001^{\star}$ \\
\hline$<2$ glasses/d & 611 & $35 \cdot 2$ & 160 & $<0.001^{*}$ & 124 & $20 \cdot 3$ & $0.047^{\star}$ & & \\
\hline$\geq 2$ glasses $/ \mathrm{d}$ & 1123 & 64.8 & 182 & & 185 & $16 \cdot 5$ & & & \\
\hline Yogurt consumption & & & & & & & & 0.037 & 0.125 \\
\hline None & 76 & 4.5 & 152 & $0.001^{*}$ & 20 & $26 \cdot 3$ & $0.046^{*}$ & & \\
\hline$\geq 1 \mathrm{cup} / \mathrm{d}$ & 1621 & 95.5 & 185 & & 270 & $16 \cdot 7$ & & & \\
\hline Dairy servings§ & & & & & & & & & \\
\hline$<2$ servings/d & 324 & $18 \cdot 8$ & 148 & $<0.001^{*}$ & 72 & $22 \cdot 2$ & $0.022^{*}$ & & \\
\hline$\geq 2$ servings $/ d$ & 1416 & 81.3 & 188 & & 238 & $16 \cdot 8$ & & & \\
\hline Cheese consumption & & & & & & & & -0.038 & 0.118 \\
\hline None & 282 & $16 \cdot 7$ & 178 & 0.45 & 48 & $17 \cdot 1$ & 0.92 & & \\
\hline$\geq 1 /$ week & 1405 & $83 \cdot 3$ & 172 & & 245 & 17.5 & & & \\
\hline Eggs consumption & & & & & & & & 0.023 & 0.332 \\
\hline$<3 /$ week & 967 & 55.5 & 170 & 0.23 & 166 & $17 \cdot 3$ & 0.77 & & \\
\hline$\geq 3 /$ week & 775 & $45 \cdot 5$ & 178 & & 139 & 18 & & & \\
\hline Area type & & & & & & & & & \\
\hline Rural & 937 & 53.5 & 168 & 0.180 & 171 & $18 \cdot 2$ & 0.670 & & \\
\hline Urban & 813 & 46.5 & 177 & & 142 & 17.5 & & & \\
\hline Parents education & & & & & & & & & \\
\hline Uneducated & 23 & $1 \cdot 2$ & 114 & $<0.001^{*}$ & & & $0.004^{*}$ & & \\
\hline Primary education & 348 & $17 \cdot 6$ & 163 & & & & & & \\
\hline Secondary education & 752 & $38 \cdot 1$ & 168 & & & & & & \\
\hline Higher education & 850 & $42 \cdot 9$ & 181 & & & & & & \\
\hline
\end{tabular}




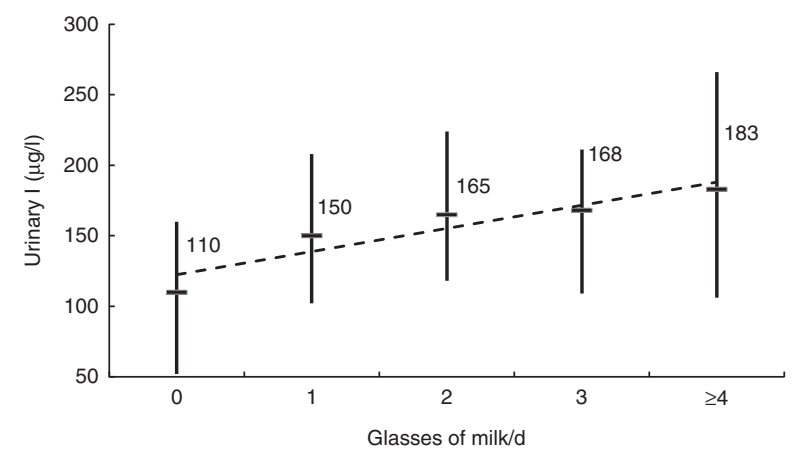

Fig. 3. Correlation between urinary iodine and milk consumption among children who did not consume iodised salt. P, percentiles; $t$, median of urinary iodine (P25, P75).

Table 4. Prevalence of thyroid dysfunction

\begin{tabular}{lclc}
\hline & & TSH levels below or above & \\
& TSH RV $(\mathrm{mU} / \mathrm{l})$ & TSH RV $(n(\%))$ & $95 \% \mathrm{Cl}(\%)$ \\
\hline Male & $0.07-1.75$ & Below: $0(0.0)$ & - \\
& & Above: $64(8.1)$ & $6.1,10.1$ \\
Female & $0.14-1.82$ & Below: $4(0.5)$ & $0.1,1.4$ \\
& & Above: $54(7.3)$ & $5.4,9.3$ \\
Overall & $0.10-1.78$ & Below: $2(0.1)$ & $0.01,0.4$ \\
& & Above: $131(7.6)$ & $6.3,8.9$ \\
\hline
\end{tabular}

TSH RV, TSH reference values in whole blood; TSH, thyroid-stimulating hormone.

design did not include a follow-up period, which would have allowed us to study the evolution of these cases. The prevalence of low TSH $(0 \cdot 1 \%)$ was similar to that observed in Galicia $(0.1 \%)$ and lower than that detected in Almeria $(0.6 \%)^{(29,30)}$.

The median TSH concentration, as well as the prevalence of elevated TSH, was significantly higher in children with a family history of hypothyroidism, in agreement with a recent study showing increased TSH concentrations in the adolescent offspring of women who had had hypothyroidism or antithyroid peroxidase (TPO) antibodies during pregnancy, as compared with those of euthyroid mothers or mothers negative for anti-TPO antibodies $^{(34)}$. The prevalence of a positive family history of thyroid diseases in children with subclinical hypothyroidism and carrying non-synonymous mutations in the TSH receptor gene is twice that of patients with no mutation ${ }^{(35)}$. Thus, our cases with family history of hypothyroidism could probably have a genetic predisposition to develop further thyroid pathology. García-García et $a l^{(30)}$ observed a prevalence of thyroid autoimmunity (TA) (between 2.4 and 5\%) directly related to I intake among children aged 1-16 years with adequate I intake. The association between I prophylaxis and induction of autoimmunity, and thus hypothyroidism, could not be confirmed in our study, as anti-TPO antibodies were not assessed.

Although six AC did not participate in the study, three (Valencia, Andalusia and Galicia) had recent available data regarding I nutrition in schoolchildren ${ }^{(18,30,36)}$, which were comparable with the present data. Thus, the lack of these data will, most likely, not cause a great deviation in our results. One other limitation of the present study is that the labelling of IS was not checked by the investigators, although parents were requested to do so. Some other limitations are the lack of anthropometric and anti-TPO antibodies data, variables that might have had some influence on TSH results, and of thyroxine, which would have helped to better assess thyroid dysfunction. Likewise, the analysis of creatinine in urine could have reduced the variability involved in casual urine sampling. Despite these limitations, the present study is the first one conducted on the I status of a representative sample of schoolchildren in Spain. I-rich foods are the most important determinants of UIC. The enKid study conducted in 3534 individuals (2-24 years old) representative of the Spanish population showed that the intake pattern along the school years (2-5 and 6-9 years) regarding dairy products and fish was very homogeneous ${ }^{(21)}$. Thus, the UI data of our 6-7-year-old children are probably similar to that of the extended group aged 2-9 years.

In conclusion, 30 years after the initiation of voluntary consumption of IS, I intake is adequate, but IS intake at home is not the only I source in recent years. Although the potential contribution of processed foods to the I status in Spanish schoolchildren might be currently lower than that in other European countries ${ }^{(37,38)}$, it is necessary to monitor and control the iodisation of foods, as a putative risk of I deficit or excess in the future might exist, while it is necessary to promote the consumption of IS to achieve the WHO target of $90 \%$ of household consumption. Prevalence of TSH above RV is high, and although in most cases it will most likely spontaneously normalise, more studies are needed to determine whether these elevated TSH concentrations are associated with an increase in TA.

\section{Acknowledgements}

The authors want to thank all participating schoolchildren and their parents, teachers, nurses, administrative staff for their valuable contribution to the study and the respective ministries of health and education of the autonomous communities for their support in conducting this study. The authors also thank Patricia Santagueda for the initial statistical analysis and Almudena PardoMateos for her assistance in the writing and editing of the manuscript. The authors specially want to acknowledge Ines Velasco, $\mathrm{MD}$, for her much appreciated help in solving all final queries regarding the manuscript and for its final editing. The authors also acknowledge the Spanish Task force on disorders related to I deficiency and thyroid dysfunction for their methodological support and advice. Finally, the authors thank the staff of MerckSerono's Medical Department, Javier Alcazar, Marcos Orellana and Enrique Granados, for their great and effective logistical support. The authors also thank Maria Lecha and Amaya Peñalva for their assistance in carrying out the test-re-test of the FFQ.

The study was funded by Merck-Serono, which provided logistical support and carried out laboratory analyses, and funds for an independent medical writer.

L. V. and M. S.-P. designed the research; L. V. analysed the data and had primary responsibility for the final content; S. D., J. J. A., J. Arena, J. P., E. G.-F., J. L. M., A. L.-G., L. M. L., A. V., Z. M., O. B., E. G., J. A. M., G. M., F. V., E. M., M. R., Y. T., P. B.-V., M. A., P. S., J. Aranda and C. G.-R. conducted the research; L. V., S. D., J. J. A., E. G.-F., C. García-Rey and I. V. wrote the 
paper; E. G.-F., J. L. M. and C. Gutiérrez-Repiso provided essential materials. All the authors read and approved the final version of the manuscript.

The authors declare that there are no conflicts of interest

\section{References}

1. Lazarus JH (2015) The importance of iodine in public health. Environ Geochem Health 37, 605-618.

2. World Health Organization (2007) Assessment of Iodine Deficiency Disorders and Monitoring Their Elimination. Geneva: WHO.

3. de Escobar GM, Obregón MJ \& del Rey FE (2007) Iodine deficiency and brain development in the first half of pregnancy. Public Health Nutr 10, 1554-1570.

4. Hynes KL, Otahal P, Hay I, et al. (2013) Mild iodine deficiency during pregnancy is associated with reduced educational outcomes in the offspring: 9-year follow-up of the gestational iodine cohort. J Clin Endocrinol Metab 98, 1954-1962.

5. Melse-Boonstra A \& MacKenzie I (2013) Iodine deficiency, thyroid function and hearing deficit: a review. Nutr Res Rev 26, 110-117.

6. Vila L (2008) Prevention and control of iodine deficiencies in Spain. Rev Esp Salud Publica 82, 371-377.

7. Andersson M, De Benoist B, Darnton-Hill I, et al. (2007) Iodine Deficiency in Europe: A Continuing Public Health Problem. Geneva: WHO.

8. Donnay S \& Vila L, Task force on disorders related to iodine deficiency and thyroid dysfunction (2012) Eradication of iodine deficiency in Spain. Close, but not there yet. Endocrinol Nutr 59, 471-473.

9. Soriguer F, Gutierrez-Repiso C, Gonzalez-Romero S, et al. (2011) Iodine concentration in cow's milk and its relation with urinary iodine concentrations in the population. Clin Nutr 30, 44-48.

10. Kaganov B, Caroli M, Mazur A, et al. (2015) Suboptimal micronutrient intake among children in Europe. Nutrients 7, 3524-3535.

11. Mihai R (2011) Physiology of the pituitary, thyroid and adrenal glands. Surg (Oxf) 29, 419-427.

12. Reinehr T (2010) Obesity and thyroid function. Mol Cell Endocrinol 316, 165-171.

13. Okten A, Akcay S, Cakir M, et al. (2006) Iodine status, thyroid function, thyroid volume and thyroid autoimmunity in patients with type 1 diabetes mellitus in an iodine-replete area. Diabetes Metab 32, 323-329.

14. Marwaha RK, Tandon N, Desai AK, et al. (2010) Reference range of thyroid hormones in healthy school-age children: country-wide data from India. Clin Biochem 43, 51-56.

15. Opalinski S, Dolinska B, Korczynski M, et al. (2012) Effect of iodine-enriched yeast supplementation of diet on performance of laying hens, egg traits, and egg iodine content. Poult Sci 91, 1627-1632.

16. Dapcich V, Salvador G, Ribas L, et al. (2004) Guía de la alimentación saludable (Guide to Healthy Eating). Barcelona: Spanish Society of Community Nutrition.

17. Solberg HE (2004) The IFCC recommendation on estimation of reference intervals. The RefVal program. Clin Chem Lab Med 42, 710-714.

18. Peris Roig B, Atienzar Herráez N, Merchante Alfaro AA, et al. (2006) Endemic goiter and iodine deficiency: are they still a reality in Spain. An Pediatr (Barc) 65, 234-240.

19. Soriguer F, García-Fuentes E, Gutierrez-Repiso C, et al. (2012) Iodine intake in the adult population. Di@bet.es study. Clin Nutr 31, 882-888.

20. Caldwell KL, Makhmudov A, Ely E, et al. (2011) Iodine status of the U.S. population, National Health and Nutrition Examination Survey, 2005-2006 and 2007-2008. Thyroid 21, 419-427.
21. Serra Majem L, Ribas Barba L, Pérez Rodrigo C, et al. (2003) Hábitos alimentarios y consumo de alimentos en la población infantil y juvenil española (1998-2000): variables socioeconómicas y geográficas (Dietary habits and food consumption in Spanish children and adolescents (1998-2000): socio-economic and demographic factors). Med Clin (Barc) 121, 126-131.

22. Capdevila Bert R, Marsal Mora JR, Pujol Salud J, et al. (2010) Estudio de prevalencia de la deficiencia de yodo en una población escolarizada de 6 años (Prevalence study of iodine deficiency in a 6-year-old school population). An Pediatr (Barc) 72, 331-338.

23. Watutantrige Fernando S, Barollo S, Nacamulli D, et al. (2013) Iodine status in schoolchildren living in northeast Italy: the importance of iodized-salt use and milk consumption. Eur J Clin Nutr 67, 366-370.

24. Vanderpump MPJ, Lazarus JH, Smyth PP, et al. (2011) Iodine status of UK schoolgirls: a cross-sectional survey. Lancet $\mathbf{3 7 7}$, 2007-2012.

25. Wengrowicz S, Saenz-Torre M, Santiago Fernandez $\mathrm{P}$, et al. (2015) Iodine content of iodised salt in Spain. Thyroid $\mathbf{2 5}$, Suppl. 1, A-81.

26. Zimmermann MB, Ito Y, Hess SY, et al. (2005) High thyroid volume in children with excess dietary iodine intakes. $\mathrm{Am} \mathrm{J}$ Clin Nutr 81, 840-844.

27. Arrizabalaga JJ, Larrañaga N, Espada M, et al. (2012) Changes in iodine nutrition status in schoolchildren from the Basque Country. Endocrinol Nutr 59, 474-484.

28. Johner SA, Thamm M \& Schmitz RRT (2015) Examination of iodine status in the German population: an example for methodological piffalls of the current approach of iodine status assessment. Eur J Nutr (Epublication ahead of print version 2 June 2015).

29. García-Mayor RV, Ríos M, Fluiters E, et al. (1999) Effect of iodine supplementation on a pediatric population with mild iodine deficiency. Thyroid 9, 1089-1093.

30. García-García E, Vázquez-López MÁ, García-Fuentes E, et al. (2012) Iodine intake and prevalence of thyroid autoimmunity and autoimmune thyroiditis in children and adolescents aged between 1 and 16 years. Eur J Endocrinol 167, 387-392.

31. Kapelari K, Kirchlechner C, Högler W, et al. (2008) Pediatric reference intervals for thyroid hormone levels from birth to adulthood: a retrospective study. BMC Endocr Disord 8, 15.

32. Lazar L, Frumkin RB, Battat E, et al. (2009) Natural history of thyroid function tests over 5 years in a large pediatric cohort. J Clin Endocrinol Metab 94, 1678-1682.

33. Johner SA, Thamm M, Stehle P, et al. (2014) Interrelations between thyrotropin levels and iodine status in thyroidhealthy children. Thyroid 24, 1071-1079.

34. Päkkilä F, Männistö T, Surcel HM, et al. (2013) Maternal thyroid dysfunction during pregnancy and thyroid function of her child in adolescence. J Clin Endocrinol Metab 98, 965-972.

35. Rapa A, Monzani A, Moia S, et al. (2009) Subclinical hypothyroidism in children and adolescents: a wide range of clinical, biochemical, and genetic factors involved. J Clin Endocrinol Metab 94, 2414-2420.

36. Rego-Iraeta A, Pérez-Fdez R, Cadarso-Suárez C, et al. (2007) Iodine nutrition in the adult population of Galicia (Spain). Thyroid 17, 161-167.

37. Varela-Moreiras G, Avila JM, Cuadrado C, et al. (2010) Evaluation of food consumption and dietary patterns in Spain by the Food Consumption Survey: updated information. Eur J Clin Nutr 64, Suppl. 3, S37-S43.

38. Slimani N, Deharveng G, Southgate DA, et al. (2009) Contribution of highly industrially processed foods to the nutrient intakes and patterns of middle-aged populations in the European Prospective Investigation into Cancer and Nutrition study. Eur J Clin Nutr 63, Suppl. 4, S206-S225. 